\title{
FACTORIAL STRUCTURE AND PSYCHOMETRIC VALIDATION OF DIGITAL EXPERIENTIAL VALUE CONSTRUCT: A CROSS-COUNTRY ANALYSIS
}

\author{
J. Saidon ${ }^{*}$, R. Musa 2 , S. A. Md Shahid ${ }^{2}$ \\ 1Faculty of Business Management, Universiti Teknologi MARA, 40450 Shah Alam, Selangor, \\ Malaysia \\ 2Institute of Business Excellence (IBE), Faculty of Business Management, Universiti Teknologi \\ MARA, 40450 Shah Alam, Selangor, Malaysia \\ *Corresponding author: saidonjb@mail.com
}

\begin{abstract}
This research disentangles and validates the underlying factorial-structure of Digital Experiential Value (DEV) measurement scale and subsequently investigate its psychometric properties. The analysis was based on a sample of 400 mobile shoppers, collected via online questionnaire. To confirm and validate the factorial structure and assess the psychometric properties of DEV, confirmatory factor analysis (CFA) was executed. To establish the homological validity of DEV, a structural model was developed to examine the effect of DEV on Total Digital Experience Quality (TDEQ). It is unveiled that DEV is a 2nd-order formative seven-factorial structure. Constructs and its scales has adequately met the psychometric criteria, thus could permit interpretation of results confidently. The findings have important implications for future research directions and management of mobile shopping industry.
\end{abstract}

Keywords: Mobile Commerce, Digital Experiential Value, Digital Engagement

\section{INTRODUCTION}

Technology has shortened distances between continents, countries, cities and people. People living in different parts of the world now have similar tastes, perceptions, styles and accessibility. A global online shopping model for e-tailers is required to address large number of diversified customers. Website developers and e-tailers need to concentrate on the motivational attributes of the websites (front offices) to attract customers. Easy interface, good layouts, updated information, multimedia contents (audio, video), effective search engines, e-catalogs, efficient navigation scheme, simple payment procedures and easy checkout process may all contribute more to consumers' motivation. This research attempts to build up a global model integrating variables from different streams and diverse literatures and applying those into a new context. The current study represents an important contribution to the theories of consumer acceptance of technology, helping researchers to know and understand the relationships among factors that constitute to the acceptance of global mobile shopping by consumers.

The major difference between mobile and Personal Computer (PC) online shopping is that the former more convenient as it allows easy access to mobile internet at any place, and any time while the latter form constraints in this area, hence customers are never restricted to a particular place or a specific time. On the same hand, the growing technology, the continuous enhancements of mobile devices and the tremendous advancement in features introduction have widely controlled the market and affected the online purchase intention.

\section{LITERATURE REVIEW}

Today, the world's economy has transcended from product and service-base to experience-based (Holbrook, 1994; Holbrook \& Hirschman, 1982). The quality experiences offered to consumers which are compelling, might have a positive impact on a retailer's ability to generate revenue (Abbade, 2014). Although quite a number of researchers have addressed consumption experience in the 
context of retail services, but there is conspicuously very limited research attempt to examine this emerging concept in the digital age with the notable exception of emotion and experience value.

This study borrows a well-known environmental psychology theory, S-O-R model by Mehrabian and Russell (1974). They postulate the interrelationship between the three variables which are stimulusorganism- response. Following the S-O-R model, this study posits that the environment cues or stimulus influences consumers' evaluation of value they obtained from the experience from the mobile site, which affects their feelings. Subsequently, their affective responses influence their behaviour. In summary, the environmental cues and interaction touch points are the stimulus (S) that influences emotional states $(\mathrm{O})$ which in turn affect behavioural response $(\mathrm{R})$. In the present research context, Digital Experiential Value (DEV) is the (S) element while Total Digital Experience Quality (TDEQ) is the (O) element which is measured based on emotional states: pleasure, arousal and dominance (PAD emotion theory). However, it is important to note that only pleasure and arousal emotion states are applicable in the current research context. Additionally, in this paper, we do not include the $\mathrm{R}$ (response) element because its main focus is to illustrate and confirm the factorial structure of DEV and to validate the psychometric properties of DEV scale.

\section{Digital Experience Value (DEV)}

The digital experience essentially delivers emotions, which are less or more intense as indicated by the type of experience. The emotion experienced and their intensity are influenced by the customer connection with others. Customer delight is characterized by positive affect and excitement that can be considered the effective element of satisfaction, which come from digital experiential value. This will influence the total digital experience quality, which will then lead to the digital engagement portrayed by consumers' through their behaviour or act.

\section{Total Digital Experience Quality (TDEQ)}

Consumers who are familiar with their smartphones are quite comfortable using the device. Therefore, whether the technology is easy to use will not influence their adoption decision. These users also have good knowledge of what m-commerce can offer and hence will not be attracted to use m-commerce based on the perceived ease of use. The mobile device is turning into multifunctional devices that are not exclusively utilized for communication purposes but also they are used for calendar, instant messaging, social networking and even playing games. That is why the researcher believes that due to the varying applications that mobile device provides to their users, this software agent can increase their pathology towards their smartphone.

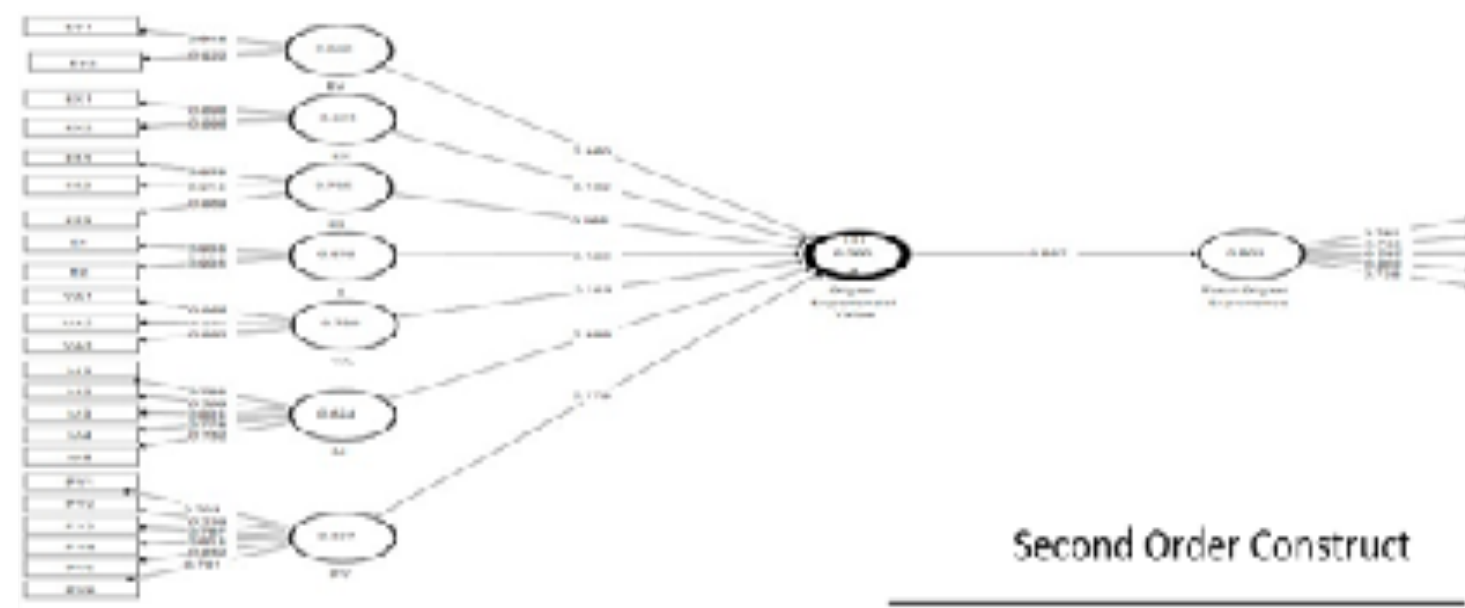

Figure 1. Results of confirmatory factor analysis for revised first-order seven factor model of (DEV)

\section{METHODOLOGY}

Using the Facebook-Ad Media method, the data was then collected through on-line questionnaire. 723 respondents qualified to proceed until the end. But after removing suspicious response cases during the data cleaning process, 585 valid and usable data was left. The usable data was then 
selected using SPSS random sample selected cases accordingly to the quota sampling table prepared. Smart Partial Least Squares (SmartPLS) are utilised to analyse total of 400 data, which comprise of 200 Malaysian and 200 Korean.

The respondents are confined to the millennial ranges from age 20 to 39 years old. Nevertheless, they must have experienced purchasing fashion product through their mobile device. The mobile device could be a mobile phone, tablet or PDA.

On the basis of exploratory research, 6 Likert scales have been adapted and extended to suit with the research setting. The scale consists of 14 items covering the subjects of economic value, excellence, escapism, entertainment and visual appeal (Mathwick et al., 2001). These factors are then added with another two factors with 11 items; mobility and personalization to suits with the digital phenomenon. This make-up total of 25 items measuring the digital experiential value.

\section{RESULTS AND DISCUSSION}

Demographics Profile of Respondents

The profile of respondents, $52 \%$ were male and 48 were female. The majority of which fall in the age category of 25 to 34 years are dominant (56\%). The distribution are summarized in Table 1.

Table 1. Respondents age distribution

\begin{tabular}{|c|c|c|}
\hline Age & Frequencies & \% \\
\hline $20-24$ & 96 & 24 \\
\hline $25-29$ & 116 & 29 \\
\hline $30-34$ & 108 & 27 \\
\hline $35-39$ & 80 & 20 \\
\hline Total & 400 & 100 \\
\hline
\end{tabular}

\section{Confirmatory Factor Analysis (CFA)}

This study employed the type II Reflective-Formative Higher order construct model. The measurement was measured by using two stage approach for convergent validity and discriminant validity. As for convergent validity; 1) factor loadings and weights 2) composite reliability 3) average variance extracted 4) collinearity statistics (VIF) and 5) outer weight t-value tests were done.

Factor loadings as the first convergent validity test, which should be more than 0.5 are summarized in Table 2. Within this study, the factor loadings were mostly exceeded 0.7. The factor loadings ranged from 0.701 to 0.938 . This is followed by second convergent validity test which is looking at the composite reliability (CR). CR should be greater than 0.7 (Hair et al., 2017). The CR ranged from 0.884 to 0.935 .

Table 2. Convergent validity (1 $1^{\text {st }}$ order $)$

\begin{tabular}{|c|c|c|c|c|}
\hline Reflective $1^{\text {st }}$ Order Constructs & Items & Loadings & $\mathbf{C R}$ & AVE \\
\hline \multirow[t]{2}{*}{ Entertainment } & E1 & 0.938 & \multirow[t]{2}{*}{0.935} & \multirow[t]{2}{*}{0.879} \\
\hline & E2 & 0.936 & & \\
\hline \multirow[t]{3}{*}{ Escapism } & ES1 & 0.878 & \multirow[t]{3}{*}{0.917} & \multirow[t]{3}{*}{0.785} \\
\hline & ES2 & 0.912 & & \\
\hline & ES3 & 0.869 & & \\
\hline Economic Value & EV1 & 0.914 & 0.914 & 0.842 \\
\hline
\end{tabular}


The Turkish Online Journal of Design, Art and Communication - TOJDAC

ISSN: 2146-5193, September 2018 Special Edition, p.747-753

\begin{tabular}{|c|c|c|c|c|}
\hline & & & \\
\hline & EV2 & 0.922 & & \\
\hline \multirow[t]{2}{*}{ Excellence } & EX1 & 0.898 & \multirow[t]{2}{*}{0.892} & \multirow[t]{2}{*}{0.805} \\
\hline & EX2 & 0.896 & & \\
\hline \multirow[t]{5}{*}{ Mobility } & M1 & 0.788 & \multirow[t]{5}{*}{0.892} & \multirow[t]{5}{*}{0.624} \\
\hline & M2 & 0.799 & & \\
\hline & M3 & 0.835 & & \\
\hline & M4 & 0.774 & & \\
\hline & M5 & 0.752 & & \\
\hline \multirow[t]{6}{*}{ Personalization } & PV1 & 0.701 & \multirow[t]{6}{*}{0.902} & \multirow[t]{6}{*}{0.607} \\
\hline & PV2 & 0.739 & & \\
\hline & PV3 & 0.767 & & \\
\hline & PV4 & 0.815 & & \\
\hline & PV5 & 0.852 & & \\
\hline & PV6 & 0.791 & & \\
\hline \multirow[t]{3}{*}{ Visual Appeal } & VA1 & 0.866 & \multirow[t]{3}{*}{0.914} & \multirow[t]{3}{*}{0.780} \\
\hline & VA2 & 0.901 & & \\
\hline & VA3 & 0.882 & & \\
\hline \multirow[t]{5}{*}{ Total Digital Experience } & TE1 & 0.762 & \multirow[t]{5}{*}{0.884} & \multirow[t]{5}{*}{0.603} \\
\hline & TE2 & 0.783 & & \\
\hline & TE3 & 0.797 & & \\
\hline & TE4 & 0.802 & & \\
\hline & TE5 & 0.738 & & \\
\hline
\end{tabular}

Thirdly, convergent validity test by looking at the Average Variance Extracted (AVE), which should be greater than 0.5 are also summarized in Table 2. The AVE of the result indicates that all the variables have a value greater than 0.5 , which means that less error remains (Hair et al., 2011) .The highest AVE is entertainment, which is 0.879 followed by economic value $(0.842)$. The lowest AVE is total digital experience, which is 0.603 . Based on Table 2, it is initiated that all of the AVE values are more than the 0.5 . Hence, all first-order variables achieved reliable and valid results as they are near to 1.0 (Hair et al., 2017).

The formative constructs proposed in the model; Digital Experiential Value, which is the second order construct as shown in Figure 1. Test of measurement quality for a second-order factor model should follow the same process that was used to examine the first-order factors (Chin, 1998a; 1998b). Therefore, the assessment in this study was conducted in two stages where the first-order constructs act as indicators in the second-order construct (Hair et al., 2010). All VIF values appeared to be below 3, which shows there were no multicollinearity issues. Therefore, the items are deemed to be reliable and are shown in Table 3. It was also found that Visual Appeal appeared as the most significant factor that influence the Digital Experiential Value, followed by Mobility and Personalization. The least significant factor was Escapism. 
Table 3. Convergent validity ( $2^{\text {nd }}$ order)

\begin{tabular}{|c|c|c|c|c|}
\hline Formative 2nd Order Constructs & Items & Weights & t-Value & VIF \\
\hline \multirow{3}{*}{ Digital Experiential Value } & Entertainment & 0.180 & 34.119 & 2.637 \\
\cline { 2 - 5 } & Escapism & 0.165 & 28.081 & 2.335 \\
\cline { 2 - 5 } & Economic Value & 0.160 & 29.743 & 1.906 \\
\cline { 2 - 5 } & Excellence & 0.169 & 31.098 & 1.935 \\
\cline { 2 - 5 } & Mobility & 0.198 & 38.419 & 2.985 \\
\cline { 2 - 5 } & Personalization & 0.178 & 36.582 & 2.218 \\
\cline { 2 - 5 } & Visual Appeal & 0.191 & 40.423 & 2.736 \\
\hline
\end{tabular}

Next, discriminant validity was measured by Fornell and Larcker (1981) as summarized in Table 4. Discriminant validity is the degree to which items differentiate among constructs at their highest level of order not inclusive of formative construct. Therefore, in this study, HTMT value are not available. From Table 1-3, we can conclude that the measures used in this study are distinct, demonstrating adequate convergent and discriminant validity. Therefore, it permits further analysis.

Table 4. Discriminant validity (Fornell \& Larcker, 1981)

\begin{tabular}{|c|c|c|}
\hline & Digital Experiential Value & Total Digital Experience \\
\hline Digital Experiential Value & NA & \\
\hline Total Digital Experience & 0.687 & 0.777 \\
\hline
\end{tabular}

Multi group analysis was done to explore whether there are differences in importance of those predictors on the digital experiential value between Malaysian and Korean mobile shoppers. The result shows that all predictors are supported. Mobility factor appeared as the most influential factors among Malaysian while Personalization factor is the most influential factors among Korean. The least influential factor for Malaysian was Escapism and for Korean was Economic Value. Digital Economic Value was found two times higher influenced on Malaysian mobile shoppers compared to Korean towards their Total Digital Experience during shopping on apparel product using their mobile device. These value are summarized in Table 5 and visualize in Figure 2.

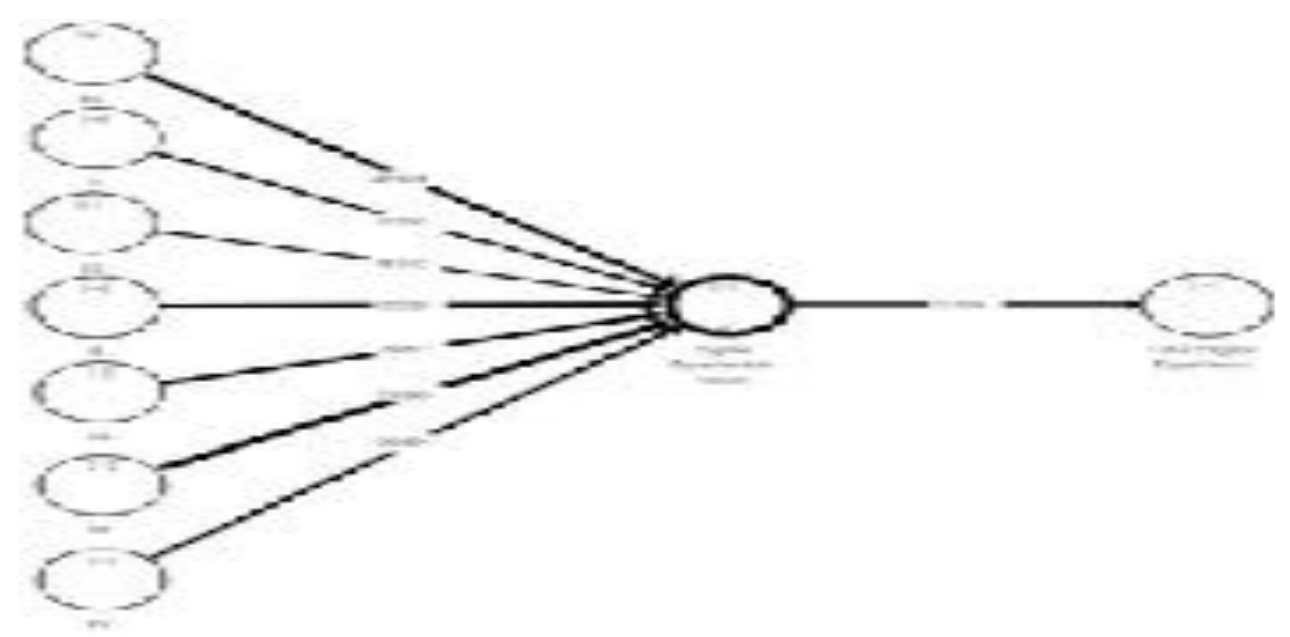

(a) 


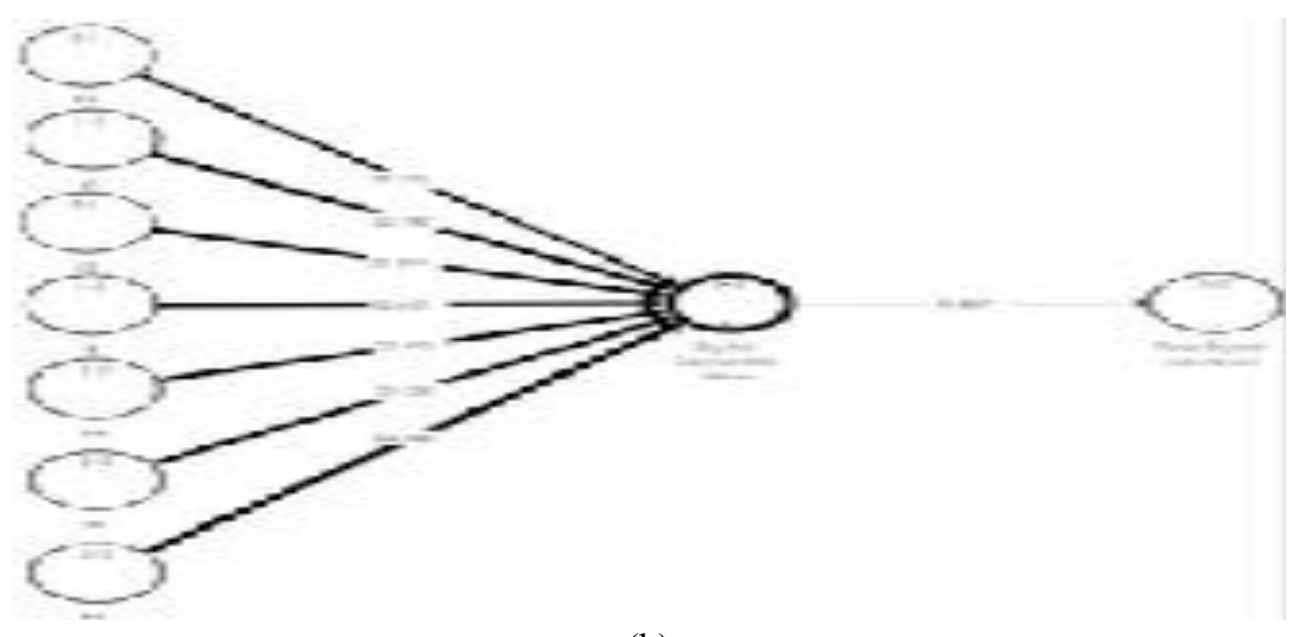

(b)

Figure 2. Multi group analysis between (a) Malaysian and (b) Korean

Table 5. Structural analysis (multi group analysis)

\begin{tabular}{|c|c|c|c|c|c|c|}
\hline & $\begin{array}{c}\text { Std. Beta } \\
\text { (Korea) }\end{array}$ & $\begin{array}{c}\text { Std. Beta } \\
\text { (Malaysia) }\end{array}$ & $\begin{array}{c}\text { t-Values } \\
\text { (Korea) }\end{array}$ & $\begin{array}{c}\text { t-Values } \\
\text { (Malaysia) }\end{array}$ & Decisions & VIF \\
\hline DEV -> TDE & 0.654 & 0.725 & 11.866 & 23.619 & Supported & 2.637 \\
\hline E -> DEV & 0.174 & 0.178 & 21.717 & 30.074 & Supported & 2.335 \\
\hline ES -> DEV & 0.184 & 0.146 & 22.130 & 16.905 & Supported & 1.906 \\
\hline EV -> DEV & 0.155 & 0.176 & 16.700 & 27.038 & Supported & 1.935 \\
\hline EX -> DEV & 0.176 & 0.158 & 22.222 & 22.144 & Supported & 2.985 \\
\hline M -> DEV & 0.194 & 0.192 & 24.669 & 34.742 & Supported & 2.218 \\
\hline PV -> DEV & 0.179 & 0.171 & 25.439 & 26.399 & Supported & 2.736 \\
\hline VA -> DEV & 0.192 & 0.189 & 24.614 & 31.337 & Supported & 2.637 \\
\hline p < 0.05 & & & & &
\end{tabular}

\section{CONCLUSION}

The results of this research afford three major contributions. First, it illustrates the factor structure or dimensionality of DEV construct. Seven factors were unveiled: economic value, excellence, escapism, entertainment, visual appeal, mobility and personalization. By performing CFA, items of DEV scale were refined to 23 items from 25 items. Secondly, it is worthy to note that Mobility and Personalization which was added into the experiential value originally developed by Mathwick et al. (2001) had shown high importance in predicting the Digital Experiential Value among the mobile shoppers. The present study is the first to validate the modified version of EVS in mobile shopping context. It should be noted that efficiency and enjoyment dimensions of EVS were found irrelevant in the present setting. The present investigation has identified two new dimensions which are mobility and personalization. Emergence of these two dimensions seems consistent with prior literature in the mobile commerce research strand. Undoubtedly, DEV can be a valuable tool to help managers and retailing operators to develop a customer typology based on the digital experiential value dimensions. This study focuses exclusively on one specific mobile commerce industry, which is the fashion industry in Malaysia and Korea. Therefore, caution should be exercised in generalizing the results to other industries. Replication studies must be undertaken to validate the findings using different industry and also across other geographical areas. In addition, the research design of using questionnaires and statistical method of analysis is often criticized in assessing the experiential aspect of consumption. The preliminary investigation 
might provide rich insights by qualitative research approach such as in-depth interviews and focus group discussion in future research. An interesting avenue for future research is to investigate the effect of DEV on mobile shopping and engagement behavior by conducting longitudinal research design. Perhaps, this potential research endeavor could afford more insightful findings.

\section{ACKNOWLEDGEMENTS}

The authors would like to thank The Ministry of Higher Education of Malaysia for providing the Fundamental Research Grant Scheme (FRGS) and Universiti Teknologi MARA for providing assistance and facilitating this research.

\section{REFERENCES}

Abbade, E. B. (2014). Technological readiness and propensity of young people to online purchases. Revista de Negócios, 19(1), 27-43.

Chin, W. W. (1998a). The partial least squares approach to structural equation modeling. Modern Methods for Business Research, 295(2), 295-336.

Chin, W. W. (1998b). Commentary: Issues and opinion on structural equation modeling. MIS Quarterly, 22(1), 7-16.

Fornell, C., \& Larcker, D. F. (1981). Evaluating structural equation models with unobservable variables and measurement error. Journal of Marketing Research, 18(1), 39-50.

Hair, J., Black, W., Babin, B., \& Anderson, R. (2010). Multivariate data analysis. Pearson Prentice Hall.

Hair Jr, J. F., Hult, G. T. M., Ringle, C., \& Sarstedt, M. (2017). A primer on partial least squares structural equation modeling (PLS-SEM). Sage Publications.

Hair, J., Sarstedt, M., Ringle, C., \& Mena, J. (2011). An assessment of the use of partial least squares structural equation modeling in marketing research. Journal of the Academy of Marketing Science, 40(3), 414-433.

Holbrook, M. B. (1994). The nature of customer value: An axiology of services in the consumption experience. In Service Quality: New Directions in Theory and Practice. Sage Publications, pp. $21-71$.

Holbrook, M. B., \& Hirschman, E. C. (1982). The experiential aspects of consumption: Consumer fantasies, feelings, and fun. Journal of Consumer Research, 9, 132-140.

Mathwick, C., Malhotra, N., \& Rigdon, E. (2001). Experiential value: Conceptualization, measurement and application in the catalog and Internet shopping environment. Journal of Retailing, 77(1), 39-56.

Mehrabian, A., \& Russell, J. A. (1974). The basic emotional impact of environments. Perceptual and Motor Skill, 38(1), 283-301. 